\title{
Anti-nutritional Factors in Afzelia afrcana and Citrullus colocynthis and Effects of the Seeds on Liver Enzyme Activities of Albino Rats
}

\author{
I. O. Igwenyi*, O. M. Ezeifedika, K. N. Agbafor, C. E. Offor, U. A. Ibiam and P. M. Aja \\ Department of Biochemistry, Ebonyi State University, P. M. B. 053, Abakaliki, Ebonyi State, Nigeria; \\ igwenyike@yahoo.com
}

\begin{abstract}
Citrullus colocynthis (melon) and Afzelia africana (akparata) are used in soup preparation as soup condiment and soup thickener respectively. The chemical compositions of these food materials were investigated to know the extent to which they contain natural substances (anti-nutrients) which may affect the metabolic and physiological response of man and animals when consumed. The anti-nutritional factors in the materials were investigated as well as the extent of toxicity on the liver when consumed even in excess, using Wister albino rats fed with varied ratios of growers mash and seed flour. The level of cyanogenic glycosides, oxalates, trypsin inhibitors were very low in all the samples and the values in both Afzelia africana and Citrullus colocynthis were $0.33 \pm 0.01$ and $1.58 \pm 0.24 \mathrm{mg} / 100 \mathrm{~g}$ of the samples respectively. The concentrations of other anti-nutrients in Afzelia africana were oxalates $1.08 \pm 0.02$, trypsin inhibitors $2.35 \pm 0.07$ and hemagluttinin $4.49 \pm 0.32$ $\mathrm{mg} / 100 \mathrm{~g}$ while the values in Citrullus colocynthis were $1.30 \pm 0.32,0.75 \pm 0.02$ and $5.63 \pm 0.43 \mathrm{mg} / 100 \mathrm{~g}$ respectively. The level of phytate was relatively higher. The concentration of tannins and alkaloids were found to be significantly high $(\mathrm{p}<0.05)$ in both samples when compared with other anti-nutrients. The values were relatively lower in the popular Citrullus colocynthis than in the unpopular Afzelia africana. The concentration of tannins in Afzelia africana and Citrullus colocynthis were $62.22 \pm 4.22$ and $49.67 \pm 3.91 \mathrm{mg} / 100 \mathrm{~g}$ while alkaloids were $59.62 \pm 4.22$ and $43.63 \pm 3.18 \mathrm{mg} / 100 \mathrm{~g}$ respectively. The investigation into the activities of the liver enzymes revealed that there was no significant difference $(p>0.05)$ in the activity of alanine transferase in all the groups when compared with the control. However, there was a significant increase $(p<0.05)$ in group B which might be considered to be dose-dependent. The activity of Aspartate Transferase (AST) increased in both groups but the increase was not significant $(p>0.05)$ when compared with the control. AST activity decreased significantly in group A ( $p>0.05)$, while alkaline phosphatase generally decreased in all the groups. There were similarities in the effects of the condiment and the thickener which were comparable. The results showed there was no significant difference in the anti-nutritional constituents and in their effects on the liver. Generally, cooking and other forms of processing such as fermentation have the ability of lowering the anti-nutritional components of food materials.
\end{abstract}

Keywords: Citrullus colocynthis, Afzelia africana, Soup, Thickener, Anti-nutrients, Enzymes.

\section{Introduction}

Food safety and security is a global problem facing all nations of the world. Over the centuries, people have obtained their food requirements from very different materials. Country, climate and culture are all determining influences. In spite of their different diets, the world people still remain healthy [14].

Citrullus colocynthis (melon) and unpopular Afzelia africana (akparata) are used in soup preparation as soup condiment and soup thickener respectively. These soups are prepared with condiments and thickeners boiled with

*Corresponding author:

I. O. Igwenyi (igwenyike@yahoo.com) 
several ingredients together to make their flavors blend, thus creating a new taste [10].

Biochemical studies of food materials investigate the chemical compositions as well as the metabolic and physiological responses of the body to diet. Thus, certain foods especially those of plant origin contain natural substances (anti-nutrients) which may be toxic to man and animals (Liener, 1980; Makkar, 1993). These non-nutrient components of foodstuff when taken by man or animals may cause several physiological changes ranging from discomfort, impairment of growth, intereference with nutrient absorption and utilization (Carnovale et al., 1988), agglutination of blood cells, inducement of cancer, nervous disorder and peharps death [3, 4]; Apena et al., 2004).

It becomes important to evaluate the anti-nutritional factors in the material and further investigate the extent of toxicity when consumed even in excess. The aim of the research is to evaluate the anti-nutritional factors in Afzelia africana and Citrullus colocynthis and their impacts on the state of the liver.

\section{Materials and Methods}

\subsection{Test Samples}

All the samples used were fresh seeds purchased from foodstuff dealers in Eke Aba Food Stuff market, Abakaliki, Ebonyi State, Nigeria. They were dried, roasted and the shells were removed manually and further dried in an oven at $60^{\circ} \mathrm{C}$ for 48 hours. They were then milled with blender to expose larger surface area and used for the study.

The test animals were male Wister albino rats that were at least eight (8) weeks old, which were arranged into three groups of four rats each. The first group served as the control, which was given only growers mash and allowed free access to water. The remaining groups $\mathrm{A}$ and $\mathrm{B}$ were given growers mash mixed with seed flour in the ratios of 2:1 and $1: 1$ respectively.

\subsection{Methods}

\subsubsection{Antinutrients (Phytochemistry)}

Generally, the spectrophotometric methods were used in the analysis of the phytochemical compositions. Methods of Harborne [13] and Okwu and Ndu [18] were used for the phytochemical analysis of antinutrients.

Investigation of the activities of liver enzymes such as alanine tranferase, aspartate transferase (the transaminases) and alkaline phosphatase were evaluated as indirect probe of its effect on the integrity of the liver using Reitman and Frankel Method [21] by monitoring the concentration of pyruvate hydrazone formed with 2, 4-dinitrophenyl hydrazine. The Aspartate transaminase activity was also determined using Reitman and Frankel Method [21], by monitoring the concentration of oxaloacetate hydrazone formed with 2,4 dinitrophenyl hydrazine. The alkaline phosphatase activities were determined using an optimized standard method according to the recommendation of Dentsche Gesellschaft fir klinische chemie (1972).

\section{Results}

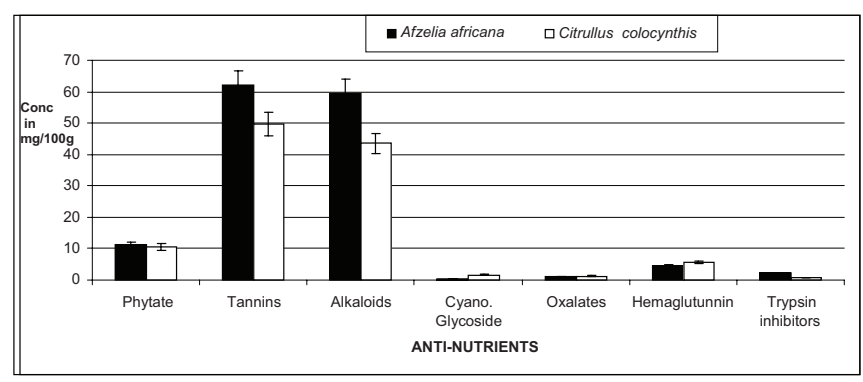

Figure 1. Anti-nutritional factors in the samples.

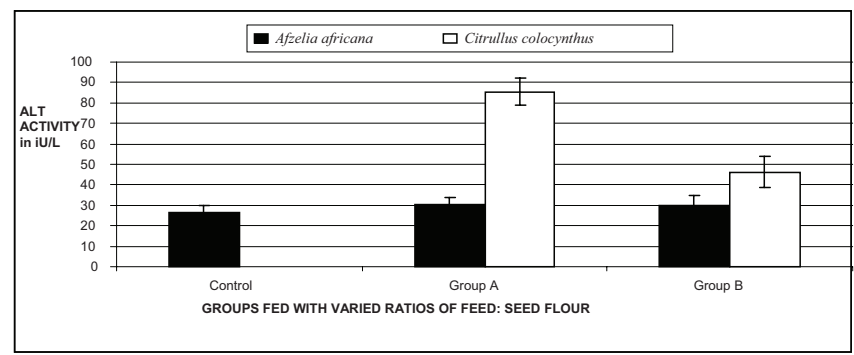

Figure 2. Alanine Transferase (ALT) activity of rats fed with seed samples.

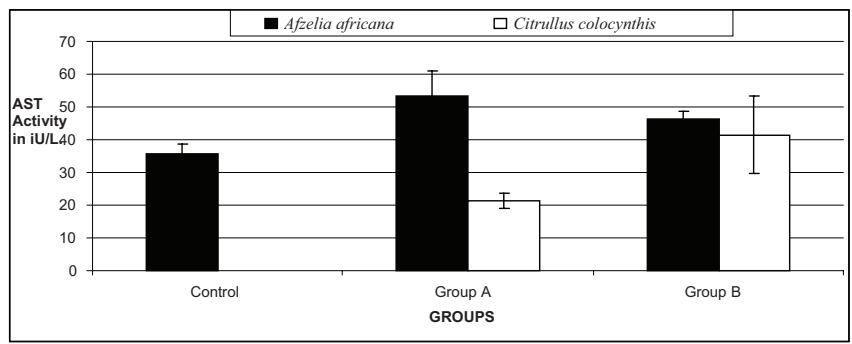

Figure 3. Aspartate Transferase (AST) activity of rats fed with seed samples. 


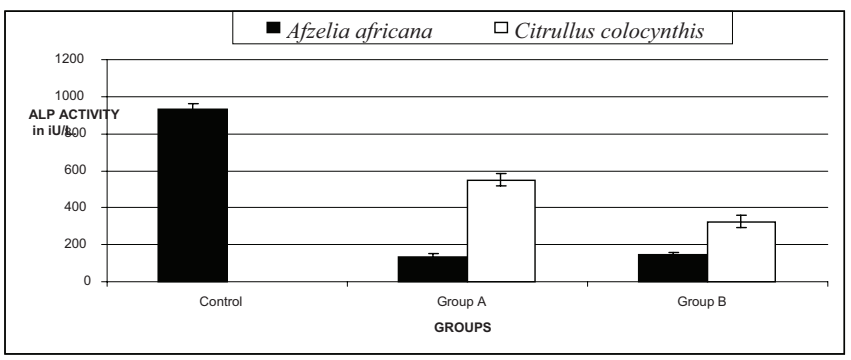

Figure 4. Alkaline Phosphatase activity of rats fed with seed samples.

\section{Discussion}

Anti-nutrients are natural or synthetic compounds that interfere with the absorption of nutrients. The level of cyanogenic glycosides, oxalates, trypsin inhibitors were very low in all the samples. The concentration of cyanogenic glycosides in both Afzelia africana and Citrullus colocynthis were $0.33 \pm 0.01$ and $1.58 \pm 0.24 \mathrm{mg} / 100 \mathrm{~g}$ of the samples respectively. The concentrations of other anti-nutrients in Afzelia africana were oxalates $1.08 \pm 0.02$, trypsin inhibitors $2.35 \pm 0.07$ and hemagluttinin $4.49 \pm 0.32 \mathrm{mg} / 100 \mathrm{~g}$ while the values in Citrullus colocynthis were $1.30 \pm 0.32,0.75 \pm 0.02$ and $5.63 \pm 0.43 \mathrm{mg} / 100 \mathrm{~g}$ respectively. The level of phytate was relatively higher. However, the increase was not significant $(\mathrm{p}>0.05)$ when compared with oxalates, hemagluttinin and trypsin inhibitors.

Oxalate occurs widely in the kingdom, and arises biosynthetically via the incomplete oxidation of carbohydrates (Fernholz, 1983). Many metal ions form insoluble precipitates with oxalate, a prominent example being calcium oxalate, the primary constituent of the most common kind of kidney stones [11]. The affinity of divalent metal ions is sometimes reflected in their tendency to form insoluble precipitates. Thus in the body, oxalic acid also combines with metals ions such as $\mathrm{Ca}^{2+}, \mathrm{Fe}^{2+}$, and $\mathrm{Mg}^{2+}$ to deposit crystals of the corresponding oxalates, which irritate the gut and kidneys. The calcium oxalate crystals or precipitate (better known as kidney stones) obstruct the kidney tubules. An estimated $80 \%$ of kidney stones are formed from calcium oxalate [9]. The values in both seeds were very low that they may not cause harm to the organism.

In many plants, cyanogenic glycosides are stored in the vacuole but if the plant is attacked they are released and become activated by enzymes in the cytoplasm. This removal of the sugar part of the molecule releases toxic hydrogen cyanide which affects oxidative phosphorylation (Voet and Voet, 2004). Storing them in inactive forms in the cytoplasm prevents them from damaging the plant under normal conditions [5]. The concentrations of the cyanogenic glycosides were significantly low in both samples that they do not pose any threat to the consumer.

Trypsin inhibitors are chemicals that reduce the availability of trypsin, an enzyme essential to nutrition of many animals, including humans [19]. Phytic acid is an antinutrient that interferes with absorption of minerals from the diet and form insoluble complexes and affect the bioavailability of minerals such as calcium, zinc, iron and magnesium (Cheryan, 1980). Hemagluttinin is majorly found in human and sometimes in plant. It is an antinutritional factor that contains iron and cytochrome that inhibit nutrient utilization in man and animals (Hughes, 1981). There were relatively low in both samples.

The concentration of tannins and alkaloids were found to be significantly high $(\mathrm{p}<0.05)$ in both samples when compared with other anti-nutrients. The values were relatively lower in the popular Citrullus colocynthis than in the unpopular Afzelia africana. The values for tannins in Afzelia africana and Citrullus colocynthis were $62.22 \pm 4.22$ and $49.67 \pm 3.91 \mathrm{mg} / 100 \mathrm{~g}$ while alkaloids were $59.62 \pm 4.22$ and $43.63 \pm 3.18 \mathrm{mg} / 100 \mathrm{~g}$ respectively.

Tannins are astringent, bitter plant polyphenols that either bind and precipitate or shrink proteins. The astringency from the tannins is what causes the dry and puckery feeling in the mouth following the consumption of red wine or an unripened fruit. They have traditionally been considered antinutritional but it is now known that their beneficial or antinutritional properties depend upon their chemical structure and dosage [16]. If ingested in excessive quantities, tannins inhibit the absorption of minerals such as iron which may, if prolonged, lead to anemia [6]. This is because tannins are metal ion chelators, and tannin-chelated metal ions are not bioavailable. This may not be bad for someone with an infection, as they interfere with the absorption of iron in the system to keep microorganisms from properly multiplying. Tannins have been shown to precipitate proteins, which inhibit in some ruminant animals the absorption of nutrients from high-tannin grains such as sorghum [6].

The concentration of tannins was very high and this has positive attributes in well-being of humans. Tannins can be effective in protecting the kidneys and have been used for immediate relief of sore throats, diarrhea, dysentery, hemorrhaging, fatigue, skin ulcers and as a cicatrizant on gangrenous wounds. Tannins can cause regression of tumors that are already present in tissue, but if used 
excessively over time, they can cause tumors in healthy tissue. Tannins are used indirectly as molluscicides to interrupt the transmission cycle of schistosomiasis. They have also reported to have anti-viral affects. When incubated with red grape juice and red wines with a high content of condensed tannins, the poliovirus, herpes simplex virus, and various enteric viruses are inactivated [2].

The alkaloids, of which over 5,500 are known, comprise the largest single class of secondary plant substances. Due to their vast nature, there is no one definition that is completely satisfactory but they generally include those basic substances which contain one or more nitrogenous atoms, usually in combination as part of a cyclic system. Alkaloids are often toxic to man and hence have dramatic physiological activities, and as a result, they are used in medicine. They are usually colourless, often optically active substances; more are crystalline but a few (e. g. nicotine) are liquid at room temperature. A simple but by no means infallible test for alkaloids in fresh leaf or fruit material is the bitter taste they often impact to the tongue. The alkaloid quinine is one of the bitterest substances known and is significantly bitter at a molar concentration of $1 \times 10^{-5}$ [13].

The result showed a low level of antinutrients that has made the food material safe for consumption. However, many traditional methods of food preparation such as fermentation, cooking, and malting increase the nutritive quality of plant foods through reducing certain anti-nutrients and such processing methods are widely used in societies where cereals and legumes form a major part of the diet. An important example of such processing is the fermentation of cassava to produce cassava flour: this fermentation reduces the levels of both toxins and anti-nutrients in the tuber [8].

The investigation into the activity of the liver enzymes revealed that there was no significant difference in the activity of alanine transferase in all the groups when compared with the control. However, there was a significant increase $(\mathrm{p}<0.05)$ in group B which might be considered to be dosedependent. The activity of Aspartate Transferase (AST) increased in both groups but the increase was not significant $(\mathrm{p}>0.05)$ when compared with the control. AST activity decreased significantly in group A ( $p>0.05)$. However, alkaline phosphatase generally decreased in all the groups.

ALT is usually present in high concentrations in the liver and to a less extent, in skeletal muscles, kidney and heart. Causes of increased levels include circulatory failure with shock and hypoxia, cirrhosis, liver congestion, cholestatic jaundice and surgery or extensive trauma and Skeletal muscle disease $[22,7]$.
AST is present in high concentration in the cells of cardiac and skeletal muscles, liver, kidney and erythrocytes. Damage to any of these tissues may increase plasma AST levels. Causes of increased level or activity include release from erythrocytes in hemolysis, myocardial infarction, acute viral or toxic hepatitis, cirrhosis, cholestatic jaundice, malignant infiltration of the kidney and skeletal muscle disease $[7,20]$.

ALP functions by splitting off phosphoric acid from organic compounds at high $\mathrm{pH}$. The primary importance of measuring ALP is to check the possibility of bone, heart and liver damage. The mucosal cells that line up the bile system of the liver are the sources of ALP. The free flow of bile through the liver and down to the biliary tract and gall bladder are responsible for maintaining proper level of this enzyme in the blood. When the liver, bile duct or gall bladder systems are not functioning properly or are blocked, this enzyme is not excreted through the bile and ALP is released into the blood. Thus, assay of the serum or tissue ALP activity is a measure of the integrity of the hepatobiliary system and the flow of bile into small intestine. Causes of increased activity are: bone disease such as rickets, liver disease and malignancy — of bone or liver involvement or direct tumor production $[7,20]$.

The activities of the liver enzymes indicated that the seeds were not hepatotoxic. The activity of alkaline phosphates decreased significantly $(p>0.05)$ in all the groups, which was an indication that there was free flow of bile through the liver, bile duct and gall bladder systems. Increased level is normally due to the blockage or non-functional state in these systems and diseases such as rickets, liver disease and malignancy of bone or liver involvement or direct tumor production [7].

In most rural communities of Africa, the use of these plant materials for food represents a very important phenomenon in traditional life and cannot be absolutely eradicated from the system even as the use of more palatable and appealing food condiments is popular among the rich and the affluent in the urban communities.

\section{References}

1. Ajiwe V I E, Okeke C A et al. (1977). Bioresource technology, Elsevier Science Limited, Britain, 259-261.

2. Bajaj Y S (1999). Medicinal and aromatic plants V, Biotechnology in Agriculture and Forestry, Springer, vol 24.

3. Bender A E, and Readi G B (1982). Toxicity of kidney beans (Phaseolus vulgaris) with special reference to lectins, Journal of Plant Foods, vol 4, 15-22. 
4. Bender A E (1983). Hemagglutinins (lectins) in beans, Journal Food Chemistry, vol 4, 309-320.

5. Benedict G, Taylor H et al. (1997). Vitamin E supplementation and molecular degeneration, Journal of Biological Chemistry, vol 23, 44-46.

6. Brune M, Rossander L et al. (1989). Iron absorption and phenolic compounds: importance of different phenolic structures, European Journal of Clinical Nutrition, vol 43(8), 547-557.

7. Burtis C A, and Ashwood E R (2003). TIETZ Fundamentals of clinical chemistry, $5^{\text {th }}$ Edn., Elsevier, New Delhi, India.

8. Champer C P, Harvey R A et al. (2005). Biochemistry: Lippincotts Illustrated Reviews, Jaypee Brothers Medical Publishers Ltd.

9. Clarkson L (1995). Nutritional biochemistry of vitamins, Cambridge University press, London.

10. Collins D, and Harry A (1994). America's Favorite Good: The Story of the Campbell Soup Company. New York.

11. Engin K N, Engin G K et al. (2007). Clinical evaluation of the neuroprotective effect of alpha tocopherol against glaucomatous damage, European Journal of Opthamology, vol 17(4), $528-533$.

12. Fernandez-Armesto F (2002). Near a thousand tables: a history of food, New York: Free Press.

13. Harborne J B (1973). Text book of phytochemical methods, A guide to modern techniques of plant analysis, $2^{\text {nd }}$ Edn., Chapman and Hall LTD, London.
14. Heimann W (1982). Fundamentals of food chemistry, $2^{\text {nd }}$ Edn., Ellis Horwood Limited, England.

15. Hughes R E (1957). Vitamin C (Ascorbic acid), Counsel Aplied Science Publishers, London, 54 -63.

16. Muller-Harvey I, and McAllan A B (1992). Tannins: their biochemistry and nutritional properties, Advances in Plant Cell Biochemistry and Biotechnology, vol 1, 151-217.

17. Ollis J B (1961). Protective actions of tannin against insects, Journal of Biological Sciences, vol 20, 133-135.

18. Okwu D E, and Ndu C U (2006). Evaluation of the phytonutrients, mineral and vitamin contents of some varieties of yam, International Journal of Molecular Medicine and Advance Sciences, vol 2(2), 199-203.

19. Pearson O A (1976). Chemical analysis of food, $7^{\text {th }}$ Edn., Chuvehill Living Stone, Edinburgh.

20. Raju S M, and Bindu M (2005). Illustrated Medical Biochemistry, Jaypee Brothers Medical Publishers LTD, New Delhi, 179-181, 323-332.

21. Reitman S, and Frankel S (1957). A colorimetric method for the determination of serum glutamic oxaloacetic and glutamic pyruvic transaminase, American Journal of clinical pathology, vol 28(1), 56-63.

22. Stryer L (1995). Biochemistry, $4^{\text {th }}$ Edn., W.H Freeman and Company, New York, 225-240.

23. Van W A K, and Van P (1997). Field guide to trees of Southern Africa, Struik, Cape Town. 